\title{
From ventilator-associated tracheobronchitis to ventilator-associated pneumonia
}

\author{
De la trachéobronchite acquise sous ventilation mécanique à la pneumonie acquise \\ sous ventilation mécanique
}

\author{
I. Martin-Loeches $\cdot$ S. Nseir $\cdot$ J. Valles $\cdot$ A. Artigas \\ Received: 20 December 2012; Accepted: 6 March 2013 \\ (C) SRLF et Springer-Verlag France 2013
}

\begin{abstract}
Ventilator-associated complications (VACs) are those complications that develop during the period of intubation. The most frequent VAC is infection. Ventilatorassociated tracheobronchitis (VAT) is one of the ventilatorassociated complications occurring in the critically ill patient. This infection represents an intermediate process between lower respiratory tract colonization and ventilator-associated pneumonia. Increased duration of mechanical ventilation has been reported in patients with VAT because of increased sputum production and airway inflammation. Two studies have shown a beneficial effect of antimicrobial treatment in patients with VAT. The optimal duration of antimicrobial treatment in patients with VAT should be further investigated because short courses of antimicrobials might be sufficient. Aerosolized antibiotics also need to be compared to systemic antibiotics in these patients.
\end{abstract}

Keywords Tracheobronchitis · Nosocomial $\cdot$ Ventilatorassociated $\cdot$ Pneumonia $\cdot$ Complication

Résumé La ventilation mécanique invasive est largement utilisée en réanimation. La trachéobronchite acquise sous ventilation mécanique (TAVM) est l'une des complications associées à cette procédure. Cette infection est difficile à différencier de la colonisation des voies respiratoires inférieures ou de la pneumonie acquise sous ventilation mécani-

I. Martin-Loeches $\cdot$ S. Nseir $(\bowtie) \cdot J$. Valles $\cdot$ A. Artigas

Critical Care Center,

Corporacion Sanitaria Universitaria Parc Tauli.

Sabadell University Hospital.

Universidad Autonoma de Barcelona.

CIBER Enfemedades Respiratorias. Sabadell, Spain

e-mail : s-nseir@chru-lille.fr

\section{S. Nseir}

Intensive Care Unit, Calmette Hospital,

University Hospital of Lille, boulevard du Professeur-Leclercq,

F-59037 Lille cedex, France que. La TAVM est associée à une prolongation de la durée de la ventilation mécanique et du séjour en réanimation en raison de l'augmentation de l'abondance des sécrétions trachéobronchiques. Deux études récentes ont suggéré que l'antibiothérapie pourrait être bénéfique chez les patients présentant cette infection. La durée optimale de l'antibiothérapie reste à déterminer, mais une antibiothérapie de courte durée devrait être appropriée. Des études randomisées devront comparer l'antibiothérapie inhalée à l'antibiothérapie systémique chez les patients présentant une TAVM.

Mots clés Trachéobronchite $\cdot$ Pneumonie $\cdot$ Ventilation mécanique $\cdot$ Complication

The use of mechanical ventilation (MV) is one of the most common artificial assistances being used in the intensive care units (ICUs). Ventilator-associated complications (VACs) are those complications that develop during the period of intubation [1]. The most frequent VAC is infection. The lower airway is an area usually sterile in healthy people; the exception is limited to patients with chronic lung diseases (chronic obstructive pulmonary disease (COPD), cystic fibrosis, and bronchiectasis). In patients under MV, endotracheal intubation, however, breaks the isolation of the lower airway and secretions coming from the oral cavity contaminated by pathogens colonizing the oropharynx. These contaminated secretions reach the lower airways and may develop respiratory infections (Fig. 1). While altered local and systemic defense mechanisms favor transition from colonization to ventilator-associated tracheobronchitis (VAT) and ventilator-associated pneumonia (VAP) [2], simple measures such as positive end-expiratory pressure prevent microaspiration of contaminated secretions and subsequent VAP $[3,4]$. This review will focus on the current understanding of the pathogenesis of VAT, modifiable risk factors, and recent approaches to treatment of this clinical entity. 


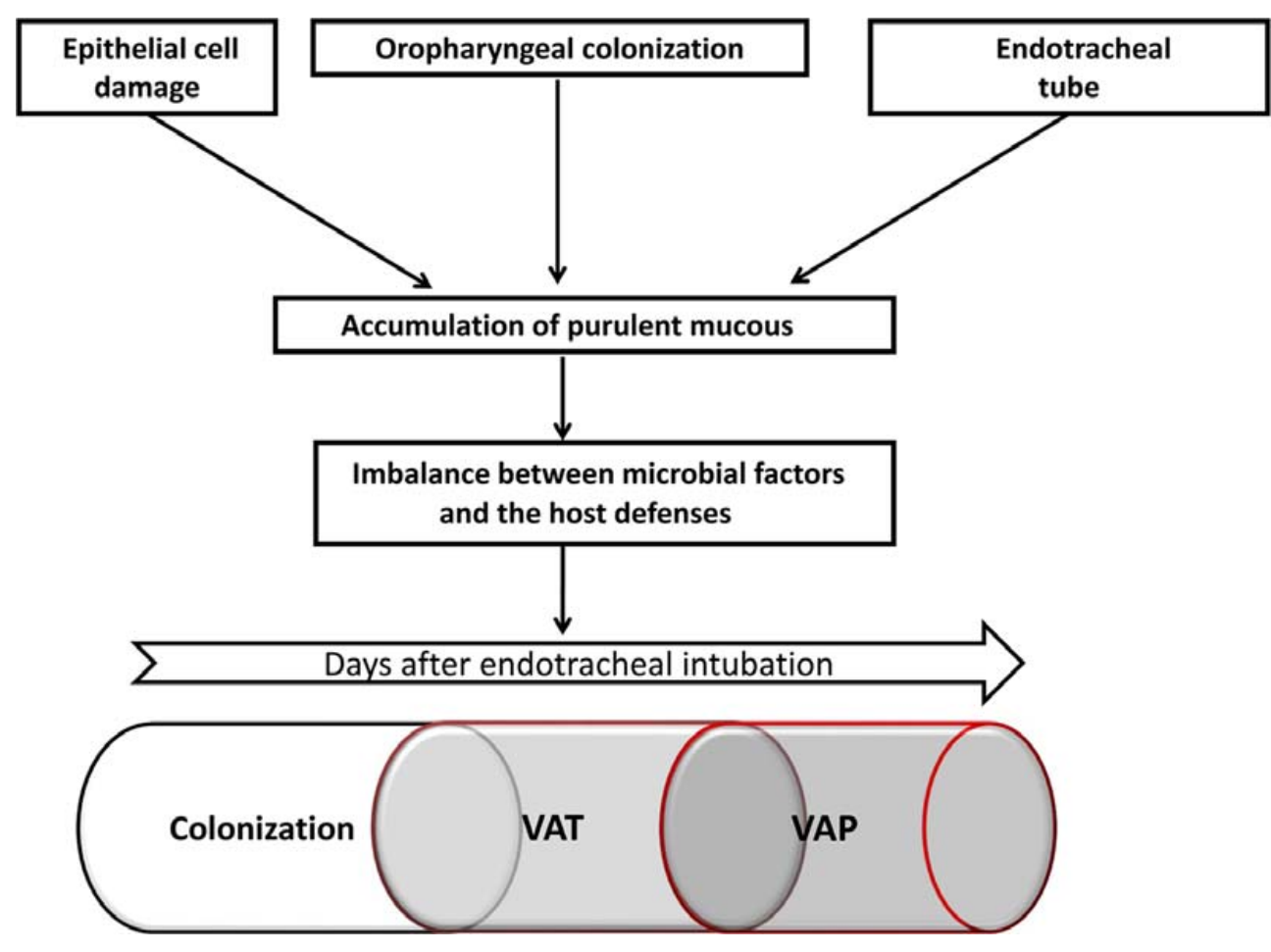

Fig. 1 Pathophysiology of development of ventilator-associated infections including tracheobronchitis (VAT) and pneumonia (VAP). Adapted from [61]

\section{From VAT to VAP}

Pneumonia is the second most frequent infectious complication in the hospital, and ranks first in ICU, whose risk is increased more than 20 times by the presence of artificial airway and is called ventilator-associated pneumonia (VAP) [5]. Whereas the information published regarding VAP in terms of diagnosis, treatment, and impact on the outcome of critically ill patients is enormous [6-8], VAT incidence is lacking and complicated in part since the definition remains controversial $[2,9,10]$. In addition, the significance of tracheobronchial colonization as risk factor for subsequent lower respiratory tract infection remains unclear [11].

The upper and lower airways can become colonized [12]. Several factors have been taken into account and do not differ from those involved in airway colonization and pneumonia development in patients under MV (Fig. 2). With the use of surveillance cultures every $48-72 \mathrm{~h}$ in patients with acute respiratory distress syndrome (ARDS), using either a protected specimen brush or bronchoalveolar lavage (BAL), VAT can occur before the onset of VAP with tracheal colonization in $56 \%$ of patients and was not predictive of VAP developing [13]. Conceivably, then, an as yet unidentified intermediate process may allow the bacterial burden to develop VAT before VAP. McDunn et al. [14] reported that the onset of an infection-specific transcrip-

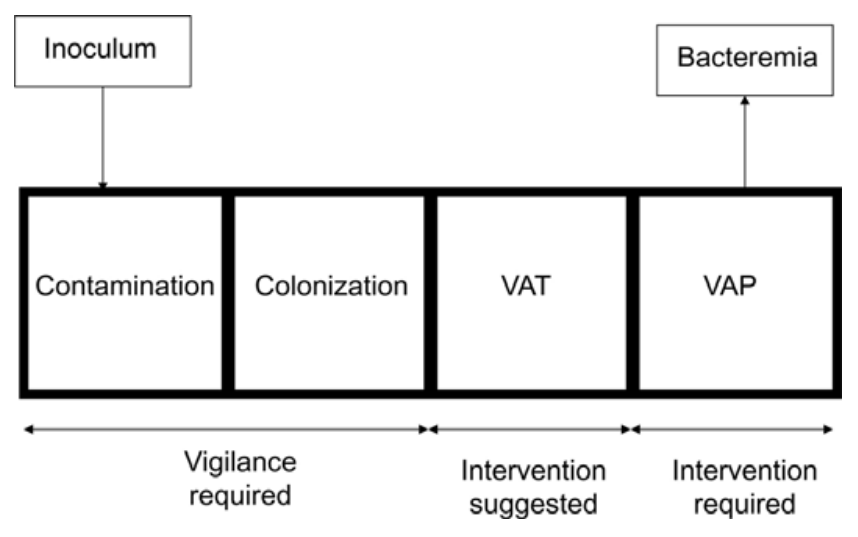

Fig. 2 The four possible interpretation of bacteria presence in a mechanically ventilated patient. Ventilator-acquired tracheobronchitis (VAT) and ventilator-acquired pneumonia (VAP)

tional program may precede the clinical diagnosis in patients who developed VAP. Our group recently published gene expression profiles in the pre-infection period, and identified a significant depression of the complement system pathway in patients who developed VAP when compared to those who developed VAT and might explain divergent pathways leading to VAT/VAP as a continuum between bronchitis and pneumonia in mechanically ventilated patients [15]. 


\section{Incidence}

Around $80 \%$ of the episodes of nosocomial pneumonia are VAP [5]. VAP affects up to $50 \%$ of patients, depending on the pathology of patients admitted in the ICU, and has an incidence density from 10 to 20 episodes per 1000 days of MV [16]. This risk is greater in the early days, and is particularly high in patients in coma, which can diagnose up to $50 \%$ of patients. Ibrahim et al. [17] reported an incidence rate of VAP of $11.5 \%, 56 \%$ of which were early onset ( $\leq 5$ day) whereas Cook et al. [18] found that the incidence per day varies over time, with $3 \%$ per day during the first 5 days of MV, $2 \%$ for the second 5 days, and $1 \%$ for the subsequent 5-day period. Therefore, the greatest attack rates appear to be during the initial days of MV. Additionally, significant risk factors for early-onset VAP include cardiopulmonary resuscitation, head injury, and continuous sedation.

A wide range of VAT incidence has been reported internationally [19-22]. The different definition criteria used in these studies might explain the important variability in VAT incidence. Malacarne et al. [19] in a prospective epidemiological study carried out in 71 Italian ICUs, with more than 9000 patients included, reported that $11.4 \%$ of the patients had an ICU-acquired infection. Tracheobronchitis was the third most common infection after pneumonia $(47 \%)$ and urinary tract infection $(26 \%)$ with an incidence of $15.5 \%$. Another study showed an incidence of VAT of $10.6 \%$, with a prevalence significantly higher in surgical $(15.3 \%)$ compared to medical patients $(9.9 \%, \mathrm{p}=0.01)$ [20]. In contrast, Dallas et al. [23] conducted an unicenter prospective study in 111 patients that aimed to differentiate the incidence of either VAP or VAT. VAT occurred less commonly than VAP $(1.4 \%$ vs. $4.0 \% ; p<0.001)$; but the occurrence of VAT was similar between surgical and medical patients $(1.3 \%$ vs. $1.5 \%, \mathrm{p}=0.845)$. Interestingly, in this study, VAT incidence was much lower than previous studies; however, this rate should be interpreted with caution as the authors did not provide any information on duration of $\mathrm{MV}$ in the whole cohort, and no information on percentage of patients with long duration of MV ( $>7$ days).

Based on Dallas et al. [23] results, VAT progressed to VAP in $32.1 \%$ of the patients, despite concurrent therapy with appropriate antibiotics based on in vitro susceptibility testing. The incidence of progression from VAT to VAP was found much than previously reported by Nseir et al. [20] (9.0\% of patients). Nseir et al. [24], however, performed a randomized trial of antibiotic therapy for VAT and found that $34 \%$ of patients with VAT developed subsequent VAP but only 3 of $22(13.6 \%)$ of these cases occurred in the group of patients that received antibiotics. Differences from these last two groups might be related to the low prevalence of COPD (known risk factor for VAT), and the absence of sur- veillance endotracheal aspirate cultures sent on admission, weekly and when VAT or VAP are suspected.

\section{Definition}

VAT diagnosis is controversial and represents an actual problem in order to define the real incidence of VAT $[25,26]$. There is currently no valid, reliable definition for VAT, and even the most widely used VAT criteria and definitions are neither sensitive nor specific. Finding a consensus definition for VAT is mandatory, so that it could be used for future studies.

Diagnosis of VAT is considered when a patient under invasive MV starts with fever, leukocytosis, and new or increased purulent secretions by the endotracheal tube. A particular difficulty with the much commonly used VAT definition (in order to distinguish from VAP) is the keypoint of the absence of pulmonary consolidation. Evidence suggests that chest radiograph findings do not accurately rule out VAP. The fact that there are many clinical entities with radiographic infiltrates (acute respiratory distress syndrome, acute pulmonary edema, atelectasis, pulmonary embolism, malignant infiltration, ...) in patients who may already present fever, and/or for other reasons leukocytosis, could complicate VAT diagnosis. Given the subjectivity and variability inherent in interpretation, chest radiograph technique in supine mechanically ventilated patients makes chest imaging ill-suited for inclusion in a definition algorithm to be used for the potential purposes of public reporting, inter-facility comparisons, and pay-for-reporting and payfor-performance programs. Therefore, distinguishing VAT from VAP represents a difficult task; several authors have proposed the use of CT lung scan in order to better characterize these infections [2]. Critically ill patients are at high risk for complications en route, and transport outside the ICU can be an independent risk factor for VAP (odds ratio: 2.9 ; 95\%confidence interval, 1.4-5.7) [27]. In addition, Self et al. [28] conducted an observational cross-sectional study of adult patients presenting to 12 emergency departments in the United States, who underwent both Chest X-ray and CT-scans for routine clinical care, and found that Chest X-ray demonstrated poor sensitivity and positive predictive value for detecting pulmonary opacities. One key-role of CT-scan can be to better define a new infiltrate that is not clearly a VAP. The most important point is probably to have a baseline X-ray and a continuous clinical assessment. Other options like lung ultrasonography might seem to be promising because of immediate bedside availability, repeatability, easy to perform but needs a specific training and further validation [29].

For the Centers for Disease Control [10], the definition of VAT in adult patients must meet the radiological criteria of absence of pneumonia in the X-ray and at least two of the following findings: 1) fever $\left.\left(>38^{\circ} \mathrm{C}\right), 2\right)$ cough, 3 ) new or increased production of sputum, 4) rhonchi and wheezing, 
and 5) bronchospasm. In addition, a positive culture of bronchial secretions obtained by endotracheal aspirate (ETA) or bronchoscopic technique should be positive. This definition seems to be sensitive enough but lacks of specificity in MV patients. With the use of a flexible bronchoscopy, additional information may help in order to accurate the diagnosis of VAT. The characteristics of secretions might be evaluated. Obtaining a deeper sample is also a relatively simple procedure that can help diagnosis [11]: if during the procedure purulent secretions come from the deep portions of the lung, the possibility of VAT diagnosis is increased [11]. However, it is important to consider, as reported by Baram et al. [30], that stable patients receiving prolonged MV without clinical pneumonia might have a high alveolar burden of bacteria.

Another major difficulty with available VAT definitions is their reliance on specific clinical signs or symptoms, which are subjective and may be poorly or inconsistently documented in the medical record. The use of inflammatory biomarkers such as procalcitonin (PCT) and C-reactive protein (CRP) can be of help; however, as it is known, controversial results have been found in VAP [31-33]. Whereas some authors found that neither PCT and CRP threshold values nor their kinetics can predict VAP survival or septic shock development, others found that the evolution of serum CRP could be related to the recognition and development of VAP. In addition, Sierra et al. [31] showed that CRP may be a good indicator of infection in patients with inflammatory response syndrome, while, more recently, Lisboa et al. [32] showed a good correlation between bacterial load measured as cfu/mL on quantitative culture of respiratory secretions and serum CRP. Whereas the use of high levels of PCT and CRP suggest a high bacterial load and a greater inflammatory response, some authors have reported that stable patients receiving prolonged MV without clinical pneumonia have a high alveolar burden of bacteria. Therefore, inflammatory biomarkers seem to help in clinical decision making for VAP, but their role in VAT diagnosis needs to be elucidated.

Finally, guidelines on hospital-acquired pneumonia and VAP has been recently published (European Respiratory Society (ERS), European Society of Clinical Microbiology and Infectious Diseases (ESCMID), and European Society of Intensive Care Medicine (ESICM)) [34]. Nosocomial tracheobronchitis definition includes: occurrence of purulent tracheal secretion after $\geq 48 \mathrm{~h}$ of hospitalization or MV plus $\geq 2$ of the following: fever $\left(\geq 38.5^{\circ} \mathrm{C}\right)$ or hypothermia $\left(<36^{\circ} \mathrm{C}\right)$, leukocytosis $\left(\geq 12 \times 10^{9} / \mathrm{L}\right)$, significant bacteriologic counts in respiratory secretions $\left(\geq 10^{3} \mathrm{cfu} / \mathrm{mL}\right.$ for protected brush specimen (PBS) and $\geq 10^{5} \mathrm{cfu} / \mathrm{mL}$ for ETA); absence of new pulmonary infiltrates compatible with pneumonia and absence of other causes of fever are mandatory. This definition needs to be further validated and can overdiagnose the incidence of VAT (and overuse of antibiotics) because the positive culture of respiratory secretions is not a mandatory item.

\section{Microbiology}

VAT is frequently caused by Gram-negative bacteria (73\%). Polymicobial VAT represents $22 \%$ of all episodes $[20,24,35]$. Pseudomonas aeruginosa (25\%), Staphylococcus aureus (21\%), and Acineobacter baumannii (17\%) are the most frequently isolated bacteria. The cut-off used by quantitative methods to diagnose VAT ranges from $10^{5}-10^{6} \mathrm{cfu} / \mathrm{mL}$. To our knowledge, no study has evaluated the accuracy of quantitative culture in diagnosing VAT. However, animal and human post-mortem studies suggested that $10^{5}-10^{6} \mathrm{cfu} / \mathrm{mL}$ for quantitative ETA was accurate in diagnosing pneumonia [36]. In addition, these studies showed that quantitative ETA had acceptable positive and negative predictive values compared to BAL.

Several recent studies suggested that routine ETA may be helpful in targeting initial antimicrobial treatment, and thus improving the rate of appropriate treatment $[37,38]$. However, none of these studies have reported on the presence of signs of infection without pulmonary infiltrate in patients with positive ETA. In addition, cost-effectiveness of routine ETA should be further investigated.

\section{Impact of ventilator-associated tracheobronchitis on outcome}

Tracheobronchitis is characterized by lower respiratory tract inflammation and increased sputum production resulting in longer duration of MV [30,39]. Extubation failure and difficult weaning have been reported to be associated with increased sputum volume in mechanically ventilated patients [40].

An observational cohort study compared outcomes between patients with VAT $(\mathrm{n}=133)$ and those with VAP $(n=77)$ in a cohort of 1241 COPD patients requiring intubation and MV for $>48 \mathrm{~h}$ [41]. No significant difference was found in duration of MV ( $26 \pm 17$ vs. $24 \pm 15$ days, $p=0.3)$ and ICU stay ( $28 \pm 20$ vs. $26 \pm 17, \mathrm{p}=0.06)$. However, ICUmortality rate was significantly lower in VAT compared with VAP patients $(45 \%$ vs. $64 \%, \mathrm{p}<0.001)$. In contrast, a recent study performed on 111 patients (28 patients with VAT and 83 patients with VAP) found no significant difference in duration of $\mathrm{MV}(16.5 \pm 13.3$ vs. $15.1 \pm 10$ days, $\mathrm{p}=0.886)$, ICU stay $(26.6 \pm 16.7$ vs. $26.6 \pm 17.3$ days, $\mathrm{p}=0.919)$, or hospital survival (78.6 vs. $80.6 \%, \mathrm{p}=0.789)$ between patients with VAT and those with VAP [23]. However, the small number of patients with VAT included in this study might explain the negative results.

In a prospective observational study including 1889 patients requiring intubation and MV, VAT was significantly associated with longer duration of MV $(24 \pm 15$ vs. $8.8 \pm 7.4$ days, $\mathrm{p}<0.001 ; 27 \pm 24$ vs. $13 \pm 12$ days, $\mathrm{p}<0.001$ ) and 
ICU stay $(31 \pm 20$ vs. $12.8 \pm 19.1$ days, $\mathrm{p}<0.001 ; 35 \pm 26$ vs. $18 \pm 15$ days, $p<0.001)$ in medical and surgical patients with or without VAT, respectively [20]. However, no significant difference was found in ICU-mortality rate between patients with VAT without subsequent VAP and those who did not develop VAT or VAP.

Because no adjustment was performed in that study for confounding factors, two matched case-control studies were conducted in patients with COPD [42] and patients without chronic respiratory disease [43]. Patients with VAP prior or subsequent to VAT were excluded in order to evaluate the specific impact of VAT on outcome. Matching criteria included 1) duration of MV prior to VAT occurrence, a control patient had to have at least the same duration of MV before VAT occurrence as a case patient; 2) primary diagnosis for admission; 3) indication for MV; 4) simplified acute physiology score II on admission \pm 5 points; 5) age \pm 5 years; and 6) date of admission when more than one potential control was well matched to a case. The first study found significantly increased duration of MV ( $21 \pm 12$ vs. $19 \pm 15$ days, $p=0.015$ ), and ICU stay ( $27 \pm 13$ vs. $24 \pm 20$ days, $\mathrm{p}=0.020$ ), in cases (VAT patients) compared with controls (patients without VAT). However, mortality rate was similar in the two groups $(40 \%$ vs. $34 \%, p=0.480)$. In the second study including patients without chronic respiratory disease, VAT was also significantly associated with longer duration of MV ( $21 \pm 16$ vs. $13 \pm 13$ days, $\mathrm{p}<0.001)$, and ICU stay $(28 \pm 15$ vs. $17 \pm 16$ days, $\mathrm{p}<0.001)$, without significant impact on ICU-mortality $(29 \%$ vs. $36 \%, p=0.294)$ in cases and controls, respectively.

\section{Impact of antimicrobial treatment on outcome in VAT patients}

The last American Thoracic Society (ATS)/Infectious Diseases Society of America (IDSA) guidelines on VAP recommended performing randomized controlled trials to determine the impact of antimicrobial treatment on outcome of VAT patients. Two recent randomized studies evaluated the impact of antimicrobial treatment on outcome of VAT patients [44]. The first was a randomized placebocontrolled blinded trial that aimed to determine the impact of aerosolized antibiotics on outcomes in patients with VAT [35]. Forty-three patients were randomized to receive aerosolized antibiotics or placebo for 14 days. The choice of aerosolized antibiotic was based on Gram stain. Vancomycin and gentamycin were used in patients with Grampositive and Gram-negative microorganisms, respectively. Both antibiotics were used if Gram-positive and Gramnegative microorganisms were present. Most of the 43 included patients were treated with systemic antibiotics because of concomitant VAP. The authors found aerosol- ized antibiotics to be associated with significantly lower rates of VAP at the end of treatment $(35.7 \%$ vs. $78.6 \%$, $\mathrm{p}=0.007$ ), reduced subsequent usage of systemic antibiotics $(42 \%$ vs. $70 \%, p=0.042)$, and higher number of days free of MV (median: 10 vs. $0, p=0.069$ ) and percentage of survivors with successful weaning ( $80 \%$ vs. $45 \%$, $\mathrm{p}=0.046$ ). Interestingly, lower rates of antimicrobial resistance were also found in patients treated with aerosolized antibiotics compared with those who received placebo $(0 \%$, vs. $16.6 \%, p=0.005)$. However, no significant impact was found on mortality $(21.1 \%$ vs. $16.7 \%, p=0.9)$. The limitations of this study included lack of specificity in VAT definition, small number of included patients, coexistence of VAP, and systemic antibiotics in most patients [45].

The impact of systemic antimicrobial treatment on outcomes in VAT patients was evaluated in a multicenter randomized unblinded controlled study [24]. In all patients, quantitative ETA was performed on ICU admission and weekly. Systemic antibiotics were given for 8 days based on results of previous ETA. The study was early stopped because planned interim analysis found significant differences in mortality rates between the two groups. Fifty-eight patients were included (22 patients in antibiotic group and 36 patients in control group). No significant difference was found between the two groups in patient characteristics at ICU admission and at randomization. Duration of MV $(29 \pm 17$ vs. $26 \pm 15$ days, $\mathrm{p}=0.816)$ and ICU stay ( $40 \pm 23$ vs. $36 \pm 21$ days, $\mathrm{p}=0.816$ ) were similar in the two groups. However, the number of days free of MV was significantly higher in antibiotic group compared with control group (median (IR) $12(8-24)$ vs. $2(0-6), p<0.001)$. In addition subsequent VAP $(13 \%$ vs. $47 \%, \mathrm{p}=0.011)$ and ICU-mortality rates $(18 \%$ vs. $47 \%, p=0.011)$ were significantly lower in antibiotic compared with control group. The lower ICU-mortality in antibiotic group might be probably related to the higher rate of VAP in control patients. Another potential explanation might be due to the difficulty in distinguishing VAT from early VAP because of the low specificity of portable chest radiograph. Limitations of this study included small number of included patients, absence of blinding, and lack of standardized antibiotic treatment [25].

A recent meta-analysis [46] included the above-discussed two randomized trials $[24,35]$, eight studies evaluating various strategies for VAT prevention (selective digestive tract decontamination (SDD) (5 studies) [47-51], automatic regulation of tracheal cuff pressure (one study) [52], oral cavity decontamination (one study) [53], and the presence of bacterial filter in the ventilator circuit (one study) [54], and other observational studies $[20,26,42]$. The authors found that administration of systemic antimicrobials (with or without aerosolized ones), as opposed to placebo or no treatment, in patients with VAT was not associated with lower mortality (odds ratio 0.56, 95\%-confidence interval, 0.27-1.14). 
However, most of the studies providing relevant data noted that administration of antimicrobial agents, as opposed to placebo or no treatment, in patients with VAT was associated with lower frequency of subsequent pneumonia and more ventilator-free days, but without shorter length of ICU stay or shorter duration of MV. In addition, SDD was not proved to be an effective preventive strategy against VAT (odds ratio $0.62,95 \%$-confidence interval, $0.27-1.14$ ).

Another hypothesis is that patients with a high bacterial load in respiratory tract could benefit from antimicrobial treatment. However, positive respiratory specimen should be considered as colonization in patients without local and systemic signs of infection. Previous studies demonstrated the beneficial effects of systemic $[55,56]$ and aerosolized [57] antibiotics in preventing early VAP in critically ill patients. However, duration of antibiotic treatment is a recognized risk factor for multidrug-resistant bacteria emergence [58]. Infections caused by these bacteria are associated with high mortality and morbidity rates [59]. A significant proportion of VAT episodes cannot be prevented, but might be treatable through pre-emptive therapy [60].

\section{Conclusions}

VAT is common in critically ill patients under MV. This infection represents an intermediate process between lower respiratory tract colonization and VAP. Increased duration of MV was reported in patients with VAT because of increased sputum production and airway inflammation. Two recent randomized controlled studies suggest that antimicrobial treatment might be associated with beneficial effects in VAT patients. Further studies should confirm the beneficial effects of antimicrobial treatment in patients with VAT. The best duration of antimicrobial treatment in patients with VAT should be investigated because short courses of antimicrobials might be sufficient. Aerosolized antibiotics might help in decreasing the bacterial load and stopping the VAT-VAP progression.

Conflict of interest: Authors have no potential conflicts of interest to declare and no involvement in any organization with a direct financial interest in the subject of the manuscript.

\section{References}

1. Kollef MH (2012) Prevention of ventilator-associated pneumonia or ventilator-associated complications: a worthy, yet challenging, goal. Crit Care Med [Internet] 40:271-7

2. Craven DE, Chroneou A, Zias N, Hjalmarson KI (2009) Ventilator-associated tracheobronchitis: the impact of targeted antibiotic therapy on patient outcomes. Chest 135:521-8
3. Manzano F, Fernández-Mondéjar E, Colmenero M, et al (2008) Positive-end expiratory pressure reduces incidence of ventilatorassociated pneumonia in nonhypoxemic patients. Crit Care Med 36:2225-31

4. Zanella A, Scaravilli V, Isgrò $\mathrm{S}$, et al (2011) Fluid leakage across tracheal tube cuff, effect of different cuff material, shape, and positive expiratory pressure: a bench-top study. Intensive Care Med 37:343-7

5. Rello J, Diaz E, Rodríguez A (2005) Advances in the management of pneumonia in the intensive care unit: review of current thinking. Clin Microbiol Infect 11(Suppl 5):30-8

6. Vidaur L, Sirgo G, Rodríguez AH, Rello J (2005) Clinical approach to the patient with suspected ventilator-associated pneumonia. Respir Care 50:965-74

7. Agbaht K, Lisboa T, Pobo A, et al (2007) Management of ventilator-associated pneumonia in a multidisciplinary intensive care unit: does trauma make a difference? Intensive Care Med 33:1387-95

8. Garnacho-Montero J, Sa-Borges M, Sole-Violan J, et al (2007) Optimal management therapy for Pseudomonas aeruginosa ventilator-associated pneumonia: an observational, multicenter study comparing monotherapy with combination antibiotic therapy. Crit Care Med 35:1888-95

9. Nseir S, Ader F, Marquette CH (2009) Nosocomial tracheobronchitis. Curr Opin Infect Dis 22:148-53

10. Garner JS, Jarvis WR, Emori TG, et al (1988) CDC definitions for nosocomial infections, 1988. Am J Infect Control 16:128-40

11. Goldberg AE, Malhotra AK, Riaz OJ, et al (2008) Predictive value of broncho-alveolar lavage fluid Gram's stain in the diagnosis of ventilator-associated pneumonia: a prospective study. J Trauma 65:871-6

12. Niederman MS, Ferranti RD, Zeigler A, et al (1984) Respiratory infection complicating long-term tracheostomy. The implication of persistent gram-negative tracheobronchial colonization. Chest $85: 39-44$

13. Delclaux C, Roupie E, Blot F, et al (1997) Lower respiratory tract colonization and infection during severe acute respiratory distress syndrome: incidence and diagnosis. Am J Respir Crit Care Med $156: 1092-8$

14. McDunn JE, Husain KD, Polpitiya AD, et al (2008) Plasticity of the systemic inflammatory response to acute infection during critical illness: development of the riboleukogram. PLoS One 3:e1564

15. Martin-Loeches I, Papiol E, Almansa R, et al (2012) Intubated patients developing tracheobronchitis or pneumonia have distinctive complement system gene expression signatures in the preinfection period: a pilot study. Med Intensiva 36:257-63

16. Olaechea PM, Ulibarrena MA, Alvarez-Lerma F, et al (2003) Factors related to hospital stay among patients with nosocomial infection acquired in the intensive care unit. Infect Control Hosp Epidemiol 24:207-13

17. Ibrahim EH, Ward S, Sherman G, Kollef MH (2000) A comparative analysis of patients with early-onset vs late-onset nosocomial pneumonia in the ICU setting. Chest 117:1434-42

18. Cook DJ, Walter SD, Cook RJ, et al (1998) Incidence of and risk factors for ventilator-associated pneumonia in critically ill patients. Ann Intern Med 129:433-40

19. Malacarne P, Langer M, Nascimben E, et al (2008) Building a continuous multicenter infection surveillance system in the intensive care unit: findings from the initial data set of 9,493 patients from 71 Italian intensive care units. Crit Care Med 36:1105-13

20. Nseir S, Di Pompeo C, Pronnier P, et al (2002) Nosocomial tracheobronchitis in mechanically ventilated patients: incidence, aetiology and outcome. Eur Respir J 20:1483-9

21. Rouby JJ, Martin De Lassale E, Poete P, et al (1992) Nosocomial bronchopneumonia in the critically ill. Histologic and bacteriologic aspects. Am Rev Respir Dis 146:1059-66 
22. Rello J, Ricart M, Ausina V, et al (1992) Pneumonia due to Haemophilus influenzae among mechanically ventilated patients. Incidence, outcome, and risk factors. Chest 102:1562-5

23. Dallas J, Skrupky L, Abebe N, et al (2011) Ventilator-associated tracheobronchitis in a mixed surgical and medical ICU population. Chest 139:513-8

24. Nseir S, Favory R, Jozefowicz E, et al (2008) Antimicrobial treatment for ventilator-associated tracheobronchitis: a randomized, controlled, multicenter study. Crit Care 12:R62

25. Craven DE (2008) Ventilator-associated tracheobronchitis (VAT): questions, answers, and a new paradigm? Crit Care 12:157

26. Torres A, Valencia M (2005) Does ventilator-associated tracheobronchitis need antibiotic treatment? Crit Care 9:255-6

27. Warren J, Fromm RE, Orr RA, et al (2004) Guidelines for the inter- and intrahospital transport of critically ill patients. Crit Care Med 32:256-62

28. Self WH, Courtney DM, McNaughton CD, et al (2013) High discordance of chest x-ray and computed tomography for detection of pulmonary opacities in ED patients: implications for diagnosing pneumonia. Am J Emerg Med 31:401-5

29. Bouhemad B, Zhang M, Lu Q, Rouby JJ (2007) Clinical review: bedside lung ultrasound in critical care practice. Crit Care 11:205

30. Baram D, Hulse G, Palmer LB (2005) Stable patients receiving prolonged mechanical ventilation have a high alveolar burden of bacteria. Chest 127:1353-7

31. Sierra R, Rello J, Bailén MA, et al (2004) C-reactive protein used as an early indicator of infection in patients with systemic inflammatory response syndrome. Intensive Care Med 30(11):2038-45

32. Lisboa T, Seligman R, Diaz E, et al (2008) C-reactive protein correlates with bacterial load and appropriate antibiotic therapy in suspected ventilator-associated pneumonia. Crit Care Med 36:166-71

33. Póvoa P, Coelho L, Almeida E, et al (2005) C-reactive protein as a marker of ventilator-associated pneumonia resolution: a pilot study. Eur Respir J 25:804-12

34. Torres A, Ewig S, Lode H, Carlet J (2009) Defining, treating and preventing hospital acquired pneumonia: European perspective. Intensive Care Med 35:9-29

35. Palmer LB, Smaldone GC, Chen JJ, et al (2008) Aerosolized antibiotics and ventilator-associated tracheobronchitis in the intensive care unit. Crit Care Med 36:2008-13

36. Nseir S, Marquette CH (2003) Diagnosis of hospital-acquired pneumonia: postmortem studies. Infect Dis Clin North Am 17:707-16

37. Michel F, Franceschini B, Berger P, et al (2005) Early antibiotic treatment for BAL-confirmed ventilator-associated pneumonia: a role for routine endotracheal aspirate cultures. Chest 127:589-97

38. Jung B, Sebbane M, Chanques G, et al (2009) Previous endotracheal aspirate allows guiding the initial treatment of ventilatorassociated pneumonia. Intensive Care Med 35:101-7

39. Palmer LB, Smaldone GC, Simon SR, et al (1998) Aerosolized antibiotics in mechanically ventilated patients: delivery and response. Crit Care Med 26:31-9

40. Epstein SK (2002) Decision to extubate. Intensive Care Med 28:535-46

41. Nseir S, Di Pompeo C, Soubrier S, et al (2005) Impact of ventilator-associated pneumonia on outcome in patients with COPD. Chest 128:1650-6

42. Nseir S, Di Pompeo C, Soubrier S, et al (2004) Outcomes of ventilated COPD patients with nosocomial tracheobronchitis: a case-control study. Infection 32:210-6

43. Nseir S, Di Pompeo C, Soubrier S, et al (2005) Effect of ventilator-associated tracheobronchitis on outcome in patients without chronic respiratory failure: a case-control study. Crit Care 9:R238-45
44. American Thoracic Society; Infectious Diseases Society of America (2005) Guidelines for the management of adults with hospitalacquired, ventilator-associated, and healthcare-associated pneumonia. Am J Respir Crit Care Med 171:388-416

45. Nseir S (2008) Aerosolized antibiotics for ventilator-associated tracheobronchitis: let's go with the flow! Crit Care Med 36:2191-2

46. Agrafiotis M, Siempos II, Falagas ME (2010) Frequency, prevention, outcome and treatment of ventilator-associated tracheobronchitis: systematic review and meta-analysis. Respir Med 104:325-36

47. Gastinne H, Wolff M, Delatour F, et al (1992) A controlled trial in intensive care units of selective decontamination of the digestive tract with nonabsorbable antibiotics. The French Study Group on Selective Decontamination of the Digestive Tract. N Engl J Med 326:594-9

48. Hammond JM, Potgieter PD, Saunders GL, Forder AA (1992) Double-blind study of selective decontamination of the digestive tract in intensive care. Lancet 340:5-9

49. Aerdts SJ, Van Dalen R, Clasener HA, et al (1991) Antibiotic prophylaxis of respiratory tract infection in mechanically ventilated patients. A prospective, blinded, randomized trial of the effect of a novel regimen. Chest 100:783-91

50. Rodríguez-Roldán JM, Altuna-Cuesta A, López A, et al (1990) Prevention of nosocomial lung infection in ventilated patients: use of an antimicrobial pharyngeal nonabsorbable paste. Crit Care Med 18:1239-42

51. Unertl K, Ruckdeschel G, Selbmann HK, et al (1987) Prevention of colonization and respiratory infections in long-term ventilated patients by local antimicrobial prophylaxis. Intensive Care Med 13:106-13

52. Valencia M, Ferrer M, Farre R, et al (2007) Automatic control of tracheal tube cuff pressure in ventilated patients in semirecumbent position: a randomized trial. Crit Care Med 35:1543-9

53. Fourrier F, Dubois D, Pronnier P, et al (2005) Effect of gingival and dental plaque antiseptic decontamination on nosocomial infections acquired in the intensive care unit: a double-blind placebo-controlled multicenter study. Crit Care Med 33:1728-35

54. Lorente L, Lecuona M, Málaga J, et al (2003) Bacterial filters in respiratory circuits: an unnecessary cost? Crit Care Med 31:2126-30

55. Acquarolo A, Urli T, Perone G, et al (2005) Antibiotic prophylaxis of early onset pneumonia in critically ill comatose patients. A randomized study. Intensive Care Med 31:510-6

56. Sirvent JM, Torres A, El-Ebiary M, et al (1997) Protective effect of intravenously administered cefuroxime against nosocomial pneumonia in patients with structural coma. Am J Respir Crit Care Med 155:1729-34

57. Falagas ME, Siempos II, Bliziotis IA, Michalopoulos A (2006) Administration of antibiotics via the respiratory tract for the prevention of ICU-acquired pneumonia: a meta-analysis of comparative trials. Crit Care 10:R123

58. Nseir S, Di Pompeo C, Diarra M, et al (2007) Relationship between immunosuppression and intensive care unit-acquired multidrug-resistant bacteria: a case-control study. Crit Care Med 35:1318-23

59. Niederman MS (2006) Use of broad-spectrum antimicrobials for the treatment of pneumonia in seriously ill patients: maximizing clinical outcomes and minimizing selection of resistant organisms. Clin Infect Dis: an official publication of the Infectious Diseases Society of America 42(Suppl 2):S72-S81

60. Vallés J, Peredro R, Burgueño MJ, et al (2013) Efficacy of singledose antibiotic against early-onset pneumonia in comatose ventilated patients. Chest (In press) doi:10.1378/chest.12-1361

61. Martin-Loeches I, Pobo A (2010) What is new in ventilatorassociated tracheobronchitis? Clin Pulm Med 17:117-21 